\title{
José Bonifácio, Shakespeare e os Gregos: a língua do Brasil e a imagem nacional
}

José Bonifácio, Shakespeare and the Greeks: the Language of Brazil and the National Image

\section{Valdei Lopes de Araujo}

Professor adjunto no Departamento de História da Universidade Federal de Ouro Preto

\section{Resumo}

Neste artigo são analisadas as relações entre política e poesia no Brasil da primeira metade do século XIX. Argumenta-se que as reflexões de Bonifácio sobre a tarefa do poeta e do tradutor são sintomas do esgotamento de um conjunto de valores clássicos que orientaram sua geração. Em 1825, Bonifácio percebeu a necessidade da produção de um novo campo de experiência capaz de orientar o jovem Império na construção de seu destino. A crise do racionalismo ilustrado, agravado pelos conflitos ao longo do processo de emancipação política, exigiu a construção de novas formas de identificação coletiva, distintas tanto do mosaico de hierarquias do período colonial, quanto do frio cosmopolitismo do racionalismo ilustrado.

\section{Abstract}

This paper analyses the relationship between politics and poetry in Brazil in the first half of the eighteenth century. José Bonifácio's reflections on poetry and translation are considered symptoms of the exhaustion of a set of classical values that have oriented his generation. In 1825 Bonifácio was conscious about the necessity of building up a new space of experience able to guide the new Brazilian Empire in the construction of its destiny. The enlightened rationalism crisis, deepened by the conflicts generated by the Brazilian Independence process, demanded the formulation of new forms of collective identity. Bonifácio tried to overcome both the colonial hierarchical mosaic of identities and the cold cosmopolitism of enlightened rationalism.

\section{Palavras-chave}

nação, Independência, literatura, modernidade

\section{Keywords}

nation, Independence, literature, modernity 
José Bonifácio de Andrada e Silva. Poesias avulsas de Américo Elysio. Bordeaux, s. ref., 1825, p. 110. (Edição fac-similar. Rio de Janeiro: Academia Brasileira de Letras, 1942) 0 trecho foi assim traduzido por Nelson Jahr Garcia: "0 olho do poeta, num delírio excelso, passa da terra ao céu, do céu à terra, e como a fantasia dá relevo a coisas até então desconhecidas, a pena do poeta Ihes dá forma, e a essa coisa nenhuma aérea e vácua empresta nome e fixa lugar certo".

0 contato pessoal, algumas vezes, e intelectual, de modo sistemático, com grandes pensadores europeus da passagem do século XVIII ao XIX, particularmente alemães (Herder, Goethe) e ingleses (Hume, Gibbon, Byron) ajuda a entender essa familiaridade. Para uma análise das viagens de Bonifácio pela Europa e o impacto em sua formação intelectual, ver Berenice Cavalcante. José Bonifácio: razão e sensibilidade, uma história em três tempos. Rio de Janeiro: Editora FGV, 2001, passim.

Afrânio Peixoto. "Apresentação" In: José Bonifácio de Andrada e Silva. Op. Cit., p. XI.

4

Cf. Antonio Candido. "Uma literatura empenhada" In: ____. Formação da literatura brasileira: momentos decisivos. Vol. I. Belo Horizonte; Rio de Janeiro: Itatiaia, 1997, pp. 26-28 e Luiz Costa Lima. "Da existência precária: o sistema intelectual no Brasil". In: _____. Dispersa Demanda: ensaios sobre literatura e teoria. Rio de Janeiro: Francisco Alves, 1981, p. 3-29

\section{Política e poesia: como imaginar a nação}

Em 1825, José Bonifácio de Andrada e Silva publica uma coletânea poética intitulada "Poesias avulsas de Américo Elysio". Após seu afastamento forçado da vida política que segue o fechamento da Assembléia Constituinte, Bonifácio encontrou tempo para voltar à atividade "poética" que os conturbados anos da Independência brasileira tornara tarefa secundária. Além de reunir poemas escritos em diferentes momentos de sua trajetória, Bonifácio apresentou uma séria de traduções, sempre acompanhadas por pequenas introduções críticas. É justamente na introdução que antecede sua tradução de algumas odes de Píndaro que encontramos a seguinte citação:

'The poet's eye, in a fine frenzy rolling,

Doth glance from heaven to earth, from earth to heaven.

And as imagination bodies forth

The form of the things unknown, the poet's pen

Turn them to shapes, and gives to airy nothing

A local habitation, and a name.' 1

A passagem é evocada na tentativa de definir a natureza da obra de Píndaro em relação ao mundo Grego. Píndaro seria o grande poeta helênico porque conseguiu traduzir em imagens a essência de seu tempo e lugar. Trata-se de um trecho de Shakespeare, isso nos é explicitamente dito por Bonifácio, embora nada registre sobre a obra específica de onde retirou a passagem. 0 conteúdo do trecho parece ser suficiente para percebermos que o Shakespeare citado por Bonifácio era aquele que emergira da releitura "pré-romântica" alemã e inglesa do clássico da literatura elisabetana. ${ }^{2}$ 0 poeta aqui não é apenas o cultor da forma, mas o gênio capaz de sondar a natureza das coisas e dar-lhes imagem, o mediador entre a comunidade e seu destino. 0 que tentaremos pensar nesse artigo é como essa nova concepção do trabalho poético está intimamente relacionado com o projeto político que emerge no processo de independência, ou seja: como produzir uma direção para aquele novo corpo político, que embora autônomo, carecia de um campo de experiência capaz de torná-lo portador de um destino compartilhado e reconhecido pelos homens que habitavam os mais diversos pontos do território.

Na história da literatura brasileira a obra poética de José Bonifácio sempre recebeu algum tipo de menção condescendente, chegando alguns a querer identificá-la como uma pré-história do romantismo brasileiro. ${ }^{3} 0$ propósito desse artigo é outro, trata-se de pensar seriamente a unidade entre política e "literatura" no nascente sistema intelectual brasileiro, e especificamente na trajetória de José Bonifácio. ${ }^{4}$

A compreensão mais comum da relação entre política e "poesia" que estava disponivel aos homens da geração da Independência passava por dois caminhos. De um lado, a "poesia" como atividade doméstica, alheia ao mundo público, rematada pelo topos clássico da amenidade e doçura da vida doméstica contraposta às agruras do mundo exterior. De outro, acompanhando a ampliação da esfera pública em sua compreensão moderna, a "poesia" tornava-se veículo de divulgação das idéias e sentimentos políticos, considerando que agora o indivíduo/cidadão está teoricamente autorizado a participar da gestão da coisa pública. Não é difícil encontrar na obra de Bonifácio referências a essas duas concepções, mas no livro de 1825 uma tarefa mais elevada passa a ser atribuída à atividade poética. 
Ente outros exemplos, ver o conjunto de "folhetos da Independência" publicados em Raymundo Faoro (org.). 0 debate político no processo da Independência. Rio de Janeiro: Conselho Federal de Cultura, 1973.

Sobre as "narrativas ilustradas", ver John G. A. Pocock. Barbarism and religion: narratives of civil government. Cambridge: Cambridge University Press, 1999

Koselleck caracterizou a aceleração do tempo histórico como uma das marcas determinantes da modernidade tal como se constitui a partir da segunda metade do século XVIII, ver, por exemplo, Reinhart Koselleck. "Modernidad" In: Futuro Pasado: para uma semántica de los tiempos históricos. Barcelona: Paidos, 1993, pp. 287-332.

8

Por cronótopo entende-se as formas historicamente estabelecidas para situar as experiências no plano temporal. Sobre esta categoria, ver Hans Ulrich Gumbrecht. "Cascatas de modernidade" In: Modernização dos sentidos. São Paulo: Ed. 34, 1998, pp. 10-11.
Buscava-se, com a referência ao bardo inglês, reforçar o entendimento da poesia como apresentação dos diversos aspectos da vida de uma comunidade humana. 0 poeta converte-se em uma espécie de narrador privilegiado, capaz de resumir, no seu texto, as diversas esferas da realidade. 0 poeta é aquele capaz de produzir imagens de uma realidade ainda não disponivel a todos, mas que passa a agir sobre o mundo através de sua obra.

Um dos pontos recorrentes no debate sobre o Brasil desde, pelo menos, 1808, é aquele que trata da natureza problemática de sua população. Os defensores da manutenção do centro do Império Português na Europa sempre recorreram ao argumento de que no Brasil não havia povo, que a população escassa e heterogênea não era fundamento suficiente para sustentar a sede do Império. ${ }^{5}$ Diversas vezes, ao longo de sua obra, Bonifácio manifestou a preocupação com a heterogeneidade da formação social no Brasil, produzindo inúmeras recomendações sobre como forjar o cidadão adequado às novas exigências do tempo. A Independência política agravou a percepção de que ao Brasil faltavam ainda elementos centrais de uma nação moderna. 0 caráter fragmentador da colonização era frequentemente lembrado como causa das divergências de interesse entre as diferentes partes do Império. A forma de resolver o dilema era integrá-lo física e moralmente. 0 poeta poderia ser o grande artífice dessa integração moral, ele poderia dar imagem e nome a tudo aquilo que para a comunidade ainda estava oculto.

Essa revalorização do trabalho poético parece acompanhar a crise do pensamento racional herdado do século XVIII. 0 modelo racional/neoclássico pressupunha a existência um caminho reto e universal para a produção de sociedades civilizadas. Os dois únicos impedimentos para a realização das narrativas ilustradas eram os preconceitos e os interesses. ${ }^{6}$ No fim das contas, mesmo o interesse parcial revelava-se como preconceito e ignorância, pois uma vez demonstrado o caminho para a melhor organização da sociedade, somente a ignorância poderia prevenir a humanidade de segui-lo. A formação intelectual de homens como Bonifácio, herdeiros de uma tradição especialmente centralizadora da ilustração portuguesa, pouco os preparara para assumir a pluralidade de interesses divergentes que a crise do mundo luso-brasileiro deixava a mostra. A razão não perecia instrumento suficiente para a unificação dos interesses, talvez a imaginação pudesse socorrê-la na tarefa de unir os homens em torno de um projeto de Estado e de Nação. No entanto, a consciência dos limites da razão e das novas funções da poesia e da imaginação é fruto de um lento processo histórico, que no Brasil acelera-se na década de $1820 .^{7}$

\section{Entre antigos e modernos}

Uma das questões recorrentes na obra de Bonifácio é o debate acerca das relações entre as culturas antiga e moderna. Se em alguns momentos ele avança na compreensão da singularidade e unidade do tempo presente, na maioria das vezes essas palavras têm um emprego apenas adjetivo, indicando os fatos mais recentes. Esse duplo registro do termo moderno parece refletir a ambigüidade entre a cronotopia européia, entendida como um avanço linear, e a cronotopia lusitana, marcada pela noção de decadência e restauração. ${ }^{8}$ Por vezes, os modernos figuram como superiores aos antigos; outras os antigos assumem seu tradicional papel normativo. Mas essa manutenção de um tempo antigo modelar, especialmente grego, está longe de um classicismo mecânico e sem profundidade histórica. As transforma- 
9

José Bonifácio de Andrada e Silva. Op. Cit., p. VI. Destaques em itálico do autor. ções na compreensão do mundo antigo alimentavam e eram alimentadas por uma nova concepção da atividade poética e literária.

É do interior desse debate que Bonifácio apresenta sua compreensão da natureza da poesia:

[...] ouso oferecer-te estes poucos e desvairados versos. [...] Fui neles assaz parco em rimas, porque a nossa bela lingua, bem como a inglesa, espanhola e italiana, não precisa, absolutamente falando, do zunzum dos consoantes para fixar a atenção e deleitar o ouvido; basta-lhe o metro e ritmo: e quanto à monotônica regularidade das estanças, que seguem à risca franceses e italianos, dela às vezes me apartei de propósito, usando da mesma soltura e liberdade, que vi novamente praticadas por um Scott e um Byron, cisnes da Inglaterra. 9

Fica evidente aqui a ambivalência com que a Antigüidade era tratada: servia como modelo idealizado quando era necessário criticar as práticas políticas dos governos modernos, mas deveria ser bem entendida quando se referia ao conteúdo da prática intelectual. Estava em jogo uma reavaliação da imagem hegemônica que se tinha do mundo antigo. Ao prescindir das rimas e fugir de grades formais herdadas, Bonifácio demonstrou plena consciência da singularidade de seus poemas. Esse novo procedimento deveria ser legitimado, para além da autoridade dos modernos, por uma dupla tarefa: desvendar o caráter da língua portuguesa, podendo trabalhar assim para seu aperfeiçoamento, e compreender o verdadeiro significado das culturas grega e romana. As duas tarefas estavam intimamente relacionadas, pois tanto o grego quanto o latim permaneciam como o melhor exemplo conhecido de línguas cujas literaturas teriam atingido a perfeição e, por isso, deveriam servir de inspiração para a compreensão do caráter e para o desenvolvimento da língua portuguesa. A persistência de um conceito de literatura entendido como um catálogo de obras a ser preenchido por cada nova civilização é indício da dificuldade em romper com os modelos clássicos. Por outro lado, assumir a necessidade de um trabalho de sondagem sobre a individualidade da língua significa dizer que ela é portadora de novidade, um tipo de especificidade frente à qual a simples aplicação de um modelo externo já não era suficiente. Desse modo, abria-se a necessidade de um tipo de análise comparativa, ou seja, que partisse do pressuposto da incomensurabilidade entre as diferentes línguas e experiência históricas.

Bonifácio insiste que a correta compreensão de frutos poéticos exigia o conhecimento da "parte estética" do Antigo Testamento, das composições gregas e latinas ou, pelo menos, dos "[...] cantos da soberba Albion, e da Germânia culta [...]". A novidade de sua poesia fazia parte de um movimento de releitura da tradição clássica ou, mais ainda, de uma reavaliação do relacionamento com a Antigüidade que autores ingleses e alemães movimentavam. Nesse caso, tratava-se mais de uma fonte de inspiração do que de modelos, permitindo ao poeta buscar, na Antigüidade, não apenas fórmulas, mas uma espécie de origem para sua poesia. Esse procedimento assumia a singularidade dessa produção poética e, ao mesmo tempo, construia uma linhagem nobre que a legitimava. Se a leitura está correta, o sentido da palavra "novamente" na frase citada acima - "usando da mesma soltura e liberdade, que vi novamente praticadas por um Scott e um Byron" - é difícil de determinar. Entendida como "recentemente", apenas afirmaria a suficiência dos modernos como fonte de autoridade na 
10

Afrânio Peixoto, em sua apresentação à reedição de 1942 das "Poesias avulsas", opta por recentemente. No entanto, para desapontamento do leitor, não diz qualquer coisa sobre os critérios que teria adotado na interpretação. Como o objetivo de seu ensaio era mostrar um Bonifácio romântico, tal escolha Ihe foi muito útil. Considerando que chega mesmo a identificar em Bonifácio uma abordagem romântica dos temas do índio e dos escravos, que obviamente não existe, aqui prefiro deixar a questão em aberto. Cf. Afrânio Peixoto. "O primeiro livro do Romantismo no Brasil". In: José Bonifácio de Andrada e Silva. Op. cit., p. XIII.

11

Conhecedor da vida intelectual germânica, tendo travado contato com vários intelectuais que realizavam percurso semelhante naquele contexto, não é de admirar que a reflexão de Bonifácio seja tão compatível com as que na "Alemanha" estavam em curso com os Humboldts, Schlegels e outros. Para uma análise comparativa dos percursos germânico e francês, ver Hans Ulrich Gumbrecht. 'Un souffle d'Allemagne ayant passé': Friedrich Diez, Gaston Paris, and the genesis of national philologies. Romance Philology, vol. XL, August 1986, pp. 1-37.

12

José Bonifácio de Andrada e Silva. Op. Cit., pp. 110-1. Grifo meu.

\section{3}

Sobre a centralidade do problema da tradução no contexto cultural germânico, em especial em Herder, ver Pierre Pénisson. "La notion de littérature nationale chez Johan Gottfried Herder". In : M. Espagne \& M. Werner. Qu'est-ce qu'une littérature nationale. Paris: Maison des sciences de I'homme, 1994, p. 117. validação de um novo procedimento poético; se lida como "de novo", justificaria a leitura de que a produção moderna repetia algo já visto em uma Antigüidade corretamente entendida. Em Bonifácio, as duas leituras seriam possiveis, e nada no restante de sua obra parece ajudar no encaminhamento de uma decisão. ${ }^{10}$

No caminho da releitura da tradição clássica havia um enorme desafio a ser vencido: a pretensão normativa do classicismo francês. ${ }^{11}$ Todo um conjunto de regras poéticas, e mesmo uma imagem do mundo antigo construído por esse classicismo, passa a ser questionado. A consciência da individualidade das línguas garantia o direito de divergir do modelo francês, cuja fonte de legitimidade, uma imagem do mundo greco-romano tida como universal, não poderia mais ser aceita sem discussão. Reavaliar a imagem da Antigüidade significava apostar não apenas na individualidade e nas diferenças, por exemplo, entre Grécia e Roma, como também no direito e dever de aperfeiçoar as línguas modernas não mais em direção a um modelo fixo, mas pela descoberta de suas vocações:

Bem sabia eu, antes de começar, que a língua portuguesa raríssimas vezes pode igualar ao laconismo e energia da grega; e todavia é a língua portuguesa bela, rica e sonora; menos dura e surda que a alemã e inglesa; mais enérgica e variada ao ouvido que a italiana; mais suave e natural que a castelhana, e superior em tudo à francesa que é mais própria para os chistes e gentilezas de salões de senhoras, que para exprimir sensações fortes e grandiosas, ou para pintar imagens poéticas atrevidas e novas; mais própria enfim para as danças de Vênus, que para os vôos de Bassareo. ${ }^{12}$

A tradução começa a desempenhar um papel fundamental no aperfeiçoamento da língua, não pela simples imitação de um modelo, mas pela comparação das diferentes qualidades e recursos de cada uma particularmente considerada. ${ }^{13} 0$ grego e o latim continuam a ser as referências fundamentais, menos como fonte de modelos e mais como exemplo de um percurso que teria realizado todas as fases de desenvolvimento, oferecendo inclusive uma literatura completa. 0 movimento é paradoxal, pois a fonte grega ainda é o melhor exemplo de literatura, por isso deve ser conhecida. No entanto, a ampliação desse conhecimento acresce a consciência da distância. A solução está, em parte, nesse contato entre as diferentes línguas, pois nelas, como produção máxima de uma cultura, ainda poderiam ser encontradas as fontes formais e históricas do que se busca imitar. A tradução é uma forma de imitação que pressupõe que já não podemos ser gregos e falar em sua língua. 0 trabalho agora é fazer os gregos falarem em português, alemão, inglês, etc. De um simples instrumento de comunicação, a língua torna-se a representação de um mundo de cultura.

As críticas ao idioma francês pontuam todo o texto de Bonifácio, sendo considerado mais talhado para as ciências duras do que para a emoção poética. 0 rigor clássico passa a significar a incapacidade para expressar as novas demandas do século, figurando o francês como uma língua enrijecida e conservadora. A valorização da tradição vernácula, que já aparecia em suas narrativas dos tempos modernos, serve como critério para explicar essas deficiências:

Por desgraça dos escritores franceses, o dialeto sonoro provençal houve de ceder o passo ao surdo e retalhado dos picardos e normandos; e a língua do belo século de Luiz XIV ficou mais monossilábica e monotônica, 
José Bonifácio de Andrada e Silva. Op. cit., p. $111-2$.

15

Ibidem, p. 114-5. Grifos meus. do que convinha ao ritmo e melodia da música e poesia. Não podendo seus poetas pelo só número e medida dos versos deleitar o ouvido, e excitar a atenção, fizeram-se escravos das rimas [...] entre os franceses verso e rima é uma e a mesma coisa, assim como nos centauros da mitologia, o homem e o cavalo. 14

Sua má vontade para com a língua francesa moderna não deve ser entendida simplesmente como uma inversão do cânone, mas como reação a uma hegemonia cultural. As línguas são estruturas singulares que podem ser aperfeiçoadas pela comparação crítica e o enriquecimento mútuo, por isso a centralidade do trabalho de tradução, que exige sempre como base a comparação.

É como se os franceses, preocupados em repetir os modelos antigos, tivessem descuidado do cultivo daquilo que sua língua teria de mais próprio. Por isso, a tradução dos clássicos não poderia ser compreendida como a simples transposição para uma língua moderna, mas como um esforço culturalmente complexo para adaptar o sentido dessas composições ao caráter da nova língua:

Para podermos pois traduzir dignamente a Píndaro, ser-nos-ia preciso enriquecer primeiro a língua com muitos vocábulos novos, principalmente compostos, como provavelmente fizeram os mesmos Homero e Píndaro para com a sua: se por fatalidade nossa o imortal Camões, que tanto tirou do latim e italiano, não ignorasse o grego, certo teria dado ao seu poema maior força e laconismo, e à língua portuguesa maior ênfase e riqueza. [...] Ousem pois os futuros engenhos brasileiros, agora que se abre nova época no vasto e nascente Império do Brasil, dar este nobre exemplo; e fico, que apesar de franzirem o beiço puristas acanhados, chegará o português, já belo e rico agora, a rivalizar em ardimento e concisão com a língua latina, de que traz a origem. ${ }^{15}$

\section{Tradução e formação nacional}

0 projeto de uma releitura da tradição clássica passava necessariamente pelo esforço da tradução. Não era mais suficiente o simples conhecimento da língua antiga. Era preciso adaptar os idiomas modernos às idéias e recursos das línguas clássicas e levar o leitor a uma correta compreensão das obras a partir de um esforço de contextualização. Na "advertência" que antepõe aos versos que traduz da Teogonia é possivel acompanhar esse procedimento e como ele levou a uma nova compreensão do que estava em jogo com a literatura:

[Na Teogonia, Hesíodo] reuniu e coordenou os mitos e tradições orais dos diversos povos e regiões da Grécia, inserindo neles os germens da filosofia fisica e teológica dos sabedores de então, para explicar as maravilhas do mundo, e firmar melhor a sociedade civil.16

Segundo essa concepção, o que se deve procurar na leitura de um escritor não são apenas os aspectos formais e modelares de sua produção, mas também todo um universo cultural que é inserido, porque não dizer, expresso, por meio da obra. Claro está que essa atividade, da forma descrita por Bonifácio, nada tem de inconsciente ou inevitável: é um gesto deliberado do autor que traça um retrato completo do estado de civilização de sua comunidade. A preocupação com o lugar e o tempo nos quais Hesíodo escreveu, discutindo inclusive se ele ou Homero poderia ser considerado 
17

Ibidem, p. 107. Grifo meu.

18

Ibidem, p. 127.

19

Ibidem, p. 108. o poeta mais antigo, indicia uma ampliação do horizonte no qual uma obra literária deveria ser situada. Isso fica mais evidente na "advertência" que antecede a tradução de algumas odes de Píndaro. Segundo Bonifácio, Píndaro

[...] foi sempre reputado entre os gregos pelo maior poeta do seu gênero. Esta opinião nacional achava-se também sancionada pelos críticos latinos [...]. Entre os modernos, que podem ter voto decisivo na matéria, ingleses e alemães são seus entusiastas, não obstante que quase toda a harmonia de seus versos é perdida para ouvidos do tempo de agora. ${ }^{17}$

0 clássico perde a transparência, mesmo a sua simples apreciação requisitava novos procedimentos capazes de aproximá-lo dos homens modernos. Essa percepção da complexidade das obras antigas, principalmente motivada pela atenção aos elementos mais sutis dessa realidade, como são a dança e a música que acompanhavam a poesia, parece apontar aos modernos uma nova e decisiva tarefa: restituir a complexidade original dessas obras. Sem dúvida, era tarefa quase impossivel, mas para a qual a própria consciência da distância já era um enorme progresso. Em sua opinião, nem mesmo os romanos tiveram a capacidade de apreciar verdadeiramente a poesia grega - as diferenças entre as duas línguas tornaria impossivel a fruição de certas sutilezas. Só um entendimento profundo do idioma e do mundo grego poderia dimensionar corretamente essas produções que durante séculos foram imitadas, mas não compreendidas.

Por exemplo, o caráter dessa tradição poética não poderia prescindir do conhecimento de que nenhuma outra nação antiga foi tão amante da música e da dança quanto a grega, de que os poemas estavam sempre unidos a essas duas outras manifestações. Sentir as emoções das odes de Píndaro exigia a consciência de que, na Grécia, as vitórias nas Olimpiadas eram mais importantes que a glória militar.

Esta nova compreensão da distância entre antigos e modernos manifesta-se, ao longo da tradução, pelo cuidadoso trabalho das notas que procuram enriquecer o texto com referências históricas, míticas, filológicas e geográficas. Por exemplo, o cuidado em explicar que "A arete dos gregos é o mesmo que a virtus dos latinos; mas não propriamente o que ora chamam virtude os moralista e teólogos. Píndaro a tomava por aquela valentia corporal, e firmeza de ânimo, que muito prezavam gregos e romanos".18

A língua deixava de ser apenas um sistema de códigos transparentes e intercambiáveis. Ou seja, o texto só se revelaria após um esforço para situálo no interior do mundo no qual fora produzido e do qual se tornava como que uma metonímia:

Sem estas considerações, muitos dos rasgos e vôos pindáricos parecerõo antes a alguns modernos partos de embriaguez, ou de cérebro desconcertado, do que inspirações de Apolo. Porém para os gregos de então que eletricismo forte Ihes não causaria o só panejamento das idéias, o desenho, claro-escuro, e proporções dos pensamentos e imagens, as continuas alusões históricas e míticas, e sobretudo o ritmo e melodia poética de uma língua, que não tinha, e nem terá outra igual em todo o mundo. ${ }^{19}$

0 fato de Bonifácio considerar essencial o domínio dessas sutilezas culturais para o entendimento de um texto é indício de que os conceitos 
20

Ibidem, p. 109. Grifo meu.

21

Essa demanda é apenas um aspecto do processo de historicização que caracteriza a modernidade ocidental. Para um panorama do problema, ver Hans Ulrich Gumbrecht. "Historicizing things" In: The Powers of Philology: dynamics of

textual scholarship. Chicago: University of Ilinois Press, 2003, pp. 54-67 e Hans Ulrich Gumbrecht. "Depois de aprender com a história" In: Em 1926: Vivendo no limite do tempo. Rio de Janeiro: Record, 1999, pp. 459-485. passavam por uma profunda reorientação, conduzida pela historicização de diversas camadas da realidade. A língua deixa de ser uma forma universal pronta para o uso intercambiável para se tornar produto de uma experiência histórica que só pode ser experimentada após um longo trabalho de reconstituição. Não seria assim explicada a distância cada vez maior que parecia afastar portugueses de diversas partes do mundo? 0 melhor sinal deste processo é o surgimento de neologismos para definir um novo campo de experiência, é o caso de religiosidade:

É de tudo isso junto, que Píndaro tece a teia de suas Odes, dandoIhe ainda novo realce e alma com rasgos de moral, e de religiosidade. Permita-se-me esta nova palavra, tomada aos alemães; visto que religiosidade e religião são coisas diferentes: um homem pode seguir uma heresia, e todavia ser muito religioso, e vice-versa. 20

Abre-se, assim, espaço para que a literatura, em seu sentido mais amplo de escritura, passe a expressar diferentes dimensões da vida humana, independente das classificações formais e retóricas dos próprios textos ou das sociedades. A experiência da nova ordem política que emergia com a Independência poderia encontrar nessa massa textual o meio para se imaginar enquanto totalidade a realizar-se em um tempo e espaço limitados e definidos historicamente.

A ruptura com a imagem abstrata da cultura antiga abre espaço para a compreensão das formas de produção das obras e de seu significado próprio em determinado lugar e tempo. 0 processo de formação das línguas e literaturas antigas passa a ser mais importante do que o seu resultado final, entendido como um momento "clássico". Esse movimento permite pensar um programa de aperfeiçoamento da língua e literatura portuguesa que se distancie do simples acrescentar de exemplos e aprimoramento formal.

A língua portuguesa, que teve em Camões sua primeira grande expansão pelo contato produtivo com o latim, deveria repetir a experiência no que se refere ao grego. Nessa nova tarefa, os brasileiros poderiam assumir a vanguarda, enfrentando preconceitos e enriquecendo a língua com novos recursos expressivos. Não se trata de criar uma língua brasileira, mas de assumir produtivamente a herança lusitana e realizar as potencialidades adquiridas ao longo de seu processo de formação. Se o velho Portugal, com Camões, apropriara-se dos recursos expressivos do latim, 0 Império do Brasil teria como missão cortar mais fundo e ir buscar no grego a inspiração e os recursos poéticos para levar a língua ao seu desenvolvimento máximo. Bonifácio não esclarece se essa relação produtiva deveria também incluir as línguas modernas, que não possuíam em seu discurso o mesmo significado do grego e do latim. Certo é, todavia, que as línguas inglesa e alemã deveriam ser admiradas por sua disposição em dialogar profundamente com a tradição antiga.

\section{O lugar das idéias e os limites da razão}

Uma das heranças intelectuais mais decisivas do momento romântico é a noção de que as idéias e produtos culturais devem expressar seu lugar de produção. Sabemos que essa exigência nem sempre existiu e que mesmo em algumas épocas seria considerada absurda. Associar as idéias e conceitos a um determinado lugar só pôde se tornar uma exigência quando eles deixaram de ser artefatos abstratos e passaram a ser concebidos como objetos situados historicamente. ${ }^{21}$ 
22

Um bom exemplo do funcionamento desse "cosmopolistismo letrado" foram as academias eruditas do século XVIII, cujas figurações brasílicas foram analisadas em Iris Kantor. Esquecidos e Renascidos: historiografia acadêmica lusoamericana (1724-1759). São Paulo: Hucitec, 2004, passim
23

Leia-se a passagem completa:

"Theseus. More strange than true. I never may believe

These antique fables, nor these fairy toys. Lovers and madmen have such seething brains, Such shaping fantasies, that apprehend More than cool reason ever comprehends. The lunatic, the lover, and the poet, Are of imagination all compact: One sees more devils than vast hell can hold, That is the madman. The lover, all as frantic, Sees Helen's beauty in a brow of Egypt: The poet's eye, in a fine frenzy rolling, Doth glance from heaven to earth, from earth to heaven.

And as imagination bodies forth

The forms of things unknown, the poet's pen Turns them to shapes, and gives to airy nothing A local habitation and a name. Such tricks hath strong imagination That, if it would but apprehend some joy, It comprehends some bringer of that joy; Or in the night, imagining some fear, How easy is a bush supposed a bear!" William Shakespeare. A midsummer night's dream. Edinburgh: Evans, 1969, p. 139.

\section{4}

Sobre os efeitos dessa crise na produção de novos conceitos de identidade, ver João Paulo Garrido Pimenta. Portugueses, americanos, brasleiros: identidades politicas na crise do Antigo Regime luso-americano. Almanack braziliense, São Paulo, n. 03, maio 2006, pp. 69-80.
Da mesma forma, a questão da tradução ou transplantação de idéias de uma cultura para outra se torna um problema complexo quando as idéias foram, para ir direto ao ponto, nacionalizadas. Durante vários séculos os letrados europeus sentiram-se fazendo parte de uma comunidade de valores produzida pelo conhecimento comum de um grupo de textos clássicos. Esse pertencimento diminuía a força dos constrangimentos locais. A existência de uma República das Letras assentava na crença de que esse conjunto de conhecimentos podia ser universalmente transmitido. Esses homens possuiam mesmo uma língua própria para suas transações, o latim, diferente daquela que falavam em suas casas e que era sua língua nativa. 22

Quando ficasse claro que o novo império que se construía nos trópicos necessitaria ser imaginado, constituído enquanto um objeto de experiência, essa reflexão sobre o poeta como um ser capaz de produzir um novo mundo a partir daquilo que apenas está suspenso na atmosfera cultural será uma achado promissor. No entanto, seria necessário retomar a citação de Shakespeare para verificar os limites da reflexão de Bonifácio sobre as funções do poeta. 0 trecho foi retirado da abertura da cena um do quinto ato de "Sonho de uma noite de verão", que mostra o cenário de um palácio em Atenas onde Theseus inicia uma reflexão sobre as semeIhanças entre o louco, o amante e o poeta no sentido de demonstrar que em todos os três a imaginação suplanta a razão. Bonifácio recorta cuidadosamente a citação de modo a isolar o poeta de seus dois companheiros indesejáveis, o amante e o louco. Com esse simples procedimento Bonifácio elimina o que no contexto da peça era central, ou seja, a oposição entre razão e imaginação, além da caracterização menos domesticada das forças da fantasia. ${ }^{23}$

0 trabalho com a língua passa a exigir um esforço criativo da mesma qualidade daquele atribuido ao poeta, ou seja, criar novas formas para experiências que até então não tinham como se expressar. Na nova era do nascente Império do Brasil os futuros poetas deveriam fazer falar do que ainda não existia, transformar em imagens e experiência comum o resultado até certo ponto inesperado do processo histórico iniciado em 1808. ${ }^{24}$ Para os homens da geração de Bonifácio as imagens reivindicadas para experimentar esse processo inédito ainda eram, em grande medida, as herdadas do mundo Antigo. Assim como o novo carecia de linguagem, a ligação fundamental do poeta com o louco e as forças irracionais que ajudam a mover a história ainda são evitadas pelo racionalismo persistente em Bonifácio. Com o louco atrás das cortinas, a compreensão do trabalho poético como inventor de mundos permanece em Bonifácio deliberada e artificial. 0 catálogo cultural que identifica na poesia de Hesíodo e Píndaro parece evocar mais o naturalista de uma História Geral do que o gênio imponderável do romantismo.

Essa compreensão da poesia como "catálogo" é facilmente identificada em certas peças poéticas de Bonifácio. Tomemos o poema "Uma tarde":

Como esta mata escura está medonha!

Não é tão feia a habitação dos Manes!

Este ribeiro triste como soa

Por entre o pardo emaranhado bosque;

E como corre vagaroso e pobre!

O sol, que já se esconde no horizonte, 
25

José Bonifácio. Op. cit., p. 61-2.

26

Sobre estas categorias, além da noção de "expansão para dentro", ver Ilmar Rohloff de Mattos. "Construtores e herdeiros. A trama dos interesses na construção da unidade política". In: István Jancsó. Independência: história e historiografia. São Paulo: Hucitec, 2005, p. 297.

27

Sobre esses projetos, ver, Ana Rosa C. da Silva. Construção da nação e escravidão no pensamento de José Bonifácio, 1783-1823. Campinas: Editora da Universidade Estadual de Campinas, 1999, passim e Valdei Lopes de Araujo. "Como transformar portugueses em brasileiros: José Bonifácio de Andrada e Silva". In: Maria Emília Prado (Org.) Tradição e modernidade no mundo Ibero-Americano. Rio de Janeiro: Grpesq Intelectuais e poder no mundo Ibero-Americano; IHGB, 2004, p. 276-277.

28

Sobre a colisão entre essas duas concepções de unidade, ver István Jancsó. "Independência, independências". In: Op. cit., pp. 19-20
0 quadro afeia mais. - 0 vento surdo

De quando em quando só as folhas move!

A rouca voz pararam temerosos

Os esquivos jacus(1) nos bastos galhos

Cheios de Caranguataes(2), das Upiubas(3).

Das asas vai lançando a fusca noite

Terror gelado; o grito agudo e triste

Nos velhos sapezais(4) dos verdes grilos

Somente soa; e o ar cheio de trevas,

Que as árvores aumentam, vem cortando

Do agoureiro morcego as tênues asas.

É este da tristeza o negro alvergue!

Tudo é medonho e triste! Só minha alma

Não farta o triste peito de tristeza! 25

Os números entre parênteses referem às notas explicativas que concretizam o sentido pedagógico e enciclopédico da composição. No rodapé o leitor encontra: "1. Os Jacus são espécies do gênero de Linné. 2. Pertecem ao gênero bromélia. 3. São árvores das matas virgens, cuja espécie presentemente não posso determinar. 4. É uma das gramíneas, que se apoderam dos terrenos estéreis, por cansados". Essa tarefa de levantamento da herança territorial já indicia a passagem de uma concepção dinástica para uma concepção nacional de território. ${ }^{26} \mathrm{~A}$ "expansão para dentro" significa aqui apropriar-se simbolicamente de um espaço que aos poucos era construido como o lugar de onde as idéias brotavam. A poesia poderia ser a atividade capaz de produzir as imagens unificadoras da comunidade, mesmo que no plano da realidade ela fosse apenas uma mistura difícil de amalgamar.

0 tom profundamente melancólico que perpassa o poema é revelador de como a aceleração do tempo histórico vivenciada entre 1822 e 1825 abalou profundamente o otimismo reformista quanto a uma natureza entendida como recurso a ser explorado pelas forças da razão. A natureza aqui resiste e mesmo inibe a ação transformadora. Em diversas oportunidades Bonifácio pôde registrar sua desilusão com o processo de Independência, afinal, os homens não eram simples matéria inerte que o filósofo pudesse manipular. As metáforas metalúrgicas que Bonifácio explorou para explicar como transformaria a herança heterogênea do regime colonial em uma nação moderna fracassaram frente à complexidade da tarefa de construir um Império nacional. 27 A nação como uma totalidade orgânica não poderia comportar a justaposição formal de um conjunto heterogêneo que antes era acomodado pelo Império Português. ${ }^{28} \mathrm{~A}$ totalização desse mosaico em narrativas unitárias seria tarefa para a geração seguinte, a geração dos construtores do Império. 